California State University, Northridge

\title{
THE EFFECTS OF DIFFERENTIAL LINGUISTIC PATTERNS \\ IN MESSAGES ATTEMPTING TO INDUCE \\ RESISTANCE TO PERSUASION
}

A thesis submitted in partial satisfaction of the requirements for the degree of Master of Arts in

Speech Communication

by

Lawrence J. Chase

June, 1972 
The thesis of Lawrence J. Chase is approved:

California State University, Northridge

May, 1972 


\section{ACKNOWLEDGMENTS}

To my advisor and friend, Dr. Michael Burgoon: a man of courage, rigor, and humanity; his commitment to this thesis was full-time, and his inspiration for me has just begun.

To.Dr. R.B. Chase, my brother: He has provided encouragement my entire life. My parents are hereby acknowledged for their faith and love.

I would also like to thank the members of my thesis committee--Dr. Charles Mudd, who introduced me to the study of rhetoric, and Professor Lloyd Welden, who introduced me to the study of communication theory.

My colleagues Donald Ellis, Norm Fontes, and John Tapia, assisted in this effort by offering their interest and friendship.

Special thanks are given to Dr. Edward Bodaken, Dr. Donald Cameron, and Dr. William Freeman, because they care.

My wife Terry didn't do anything for this thesis, except that she made it worth doing. 
TABIE OF CONTENTS

Page

ACKNOWLEDGMENTS . . . . . . . . . . . . . . . 111

ABSTRACT - . . . . . . . . . . . . . . . . vii

Chapter

I INTRODUCIION . . . . . . . . . . . . 1

II METHODS . . . . . . . . . . 16

PROCEDURE. • . . . . . . . . . . . 17

II RESULTS • . . . . . . . . . . 25

IV DISCUSSION. . . . . . . . . . . 34

Implications for Future Research . . . 37

Summary . . • . • • . . . . 39

BIBLIOGRAPHI . . . . . . . . . . . . . . . 42

APPENDICES

A Pretest Attitude Questionnaire ..... 44

B Posttest Attitude Questionnaire . . . . 48

C Message Manipulations .. . . . . . 52 


\section{IIST OF TABLES}

Table

Page

1 Weighted scale values of the experimental words.............. 24

2 Means, standard deviations, and analysis of variance of pretest attitude scores for experimental and control groups . . .

3 Attitude scores, amount of change, and analysis of variance of attitude change scores of experimental and control groups . . . . . . . . . . . .

4 Analysis of differences of attitude change scores between each experimental group and control... . . . . . . . .

5 Analysis of Variance for the Mean Change Scores for Experimental Groups. . . . .

6 Comparisons of mean change scores of experimental groups ... . . . . . .

7 Individual Comparisons Using Scheffe's t-test to compare each experimental groups mean attitude change score to the Control Group .............. 


\section{IIST OF FIGURES}

Figure

Page

1 The Experimental Design . . . . . . . 17 


\section{ABSTRACT \\ THE EFFECTS OF DIFFERENTIAL LINGUISTIC PATTERNS \\ IN MESSAGES ATTEMPTING TO INDUCE \\ RESISTANCE TO PERSUASION \\ by}

Lawrence J. Chase

Master of Arts in Speech Communication

June, 1972

A relatively small amount of research in persuasion has sought to discover how to make people more resistant to change. Research on the induction of resistance to persuasion has generally been concerned with demonstrating the relative efficacy of the supportive and refutational pretreatment message strategies. As a result of the emphasis placed upon pretreatment message types as the primary independent variable, little attention has been given to other message variables. The purpose of this study was twofold: 1) to examine the effects of language intensity upon inducing resistance to persuasion, and 2) the investigation of the effects of differing pretreatment strategies upon impending persuasive appeals.

It was predicted that subjects would exhibit 
greater resistance to persuasion after having been exposed to a supportive pretreatment message of high intensity than would subjects who had been treated with a moderate or low intensity message.

It was also predicted that subjects exposed to a refutational message using language of moderate intensity would exhibit significantly more resistance to persuasion than would those subjects exposed to either a high or low intensity refutational pretreatment message.

The experimental messages were created utilizing a procedure developed by Burgoon and Miller (1971). Supportive and Refutational messages were created which varied in language intensity to yield high, moderate, or low intensity messages. Eleven key words/phrases taken from a word list developed by Thrustone and Jones (1955) were inserted into the experimental messages, to determine the intensity of the messages.

Attitude change was measured by subtracting pretest scores from posttest scores. Subjects evaluated the experimental issue on four seven-interval semantic differential-type scales.

The findings support both theoretical hypotheses. Subjects in the Supportive: High conditions exhibited significantly less attitude change than did those in either the Supportive: Moderate or Supportive: Low conditions. Moreover, those subjects in the Supportive: Moderate 
condition changed significantly less than did those subjects in the Supportive: Low condition. Subjects in the Refutational: Moderate condition exhibited significantly less attitude change than did subjects in either the Refutational: High or Refutational: Low conditions. Findings were discussed in terms of prior research in conferring resistance to persuasion. A number of research extensions, suggested by the findings of this study, were discussed. 
CHAPTER I

INTRODUCTION

\section{The Problem}

For thousands of years, philosophers, rhetoricians, and politicians have examined, described, and prescribed methods of influencing the attitudes of their fellow men. Classes taught within the speech communication discipline, particularly rhetorical theory, persuasion, and argumentation have been concerned with the theory and practice of persuasive communication. Most of the writing on persuasion has been directed at showing ways in which beliefs can be changed. However, there exists another dimension to the study of persuasion, although comparatively little work has been done in this area. It involves the reinforcement of already-held beliefs--of making attitudes and behaviors more resistant to change.

Research aimed at conferring resistance to persuasion, and thus minimizing attitude change, has shown that such resistance can be induced in a number of different ways. One of the most successful methods involves pretreating subjects with various types of messages prior to a persuasive attack. This investigation will utilize such a strategy. In addition, the language intensity of 
the pretreatment messages will be varied so that the effects of linguistic variance upon inducing resistance to persuasion may be studied. It is our contention that language intensity can be an important variable in conferring such resistance.

Therefore, the purposes of the investigation are:

1) the investigation of differing pretreatment strategies upon impending persuasive appeals, and 2) to examine the effects of language intensity upon inducing resistance to persuasion.

Inducing Resistance to Persuasion

Miller and Burgoon (1972) accept the position that: "a process should not be labeled 'persuasive communication' unless behavioral and attitudinal modifications result primarily from the effects of symbolization" (p. 13). Persuasion is a process "in which the persuador strives to establish particular relationships between his own attitudinal or behavioral states and those of the persuadee" (p. 15). Thus, persuasion may act as facilitator or inhibitor of change; it is a two-dimensional process.

Bettinghaus (1968) specifies four factors which are of major concern from the standpoint of a receiver in a persuasive communication. These factors are of particular relevance to this study, in that the effects of persuasive appeals are examined in terms of the lack of change in the 
attitude of the receiver. These factors are: 1) variations within the source, 2) variations within the message, 3) differences in the channel used, and 4) variations in the situation. This investigation is concerned with variations within the message, with the understanding that the aforementioned factors are in no way separate or distinct influences, and that often such factors tend to interact with other variables in the communication situation.

\section{Strategy Considerations}

In a comprehensive review, McGuire (1964) explores some of the contemporary approaches to inducing resistance to persuasion. A brief review of these approaches follows.

Behavioral-commitment approach. This approach requires that the subject "commit" himself on the basis of his belief. The four levels of commitment discussed by McGuire include, in increasing order: 1) private belief, which is anything which might force an individual to make a private decision; 2) public endorsement, where an individual must commit himself publicly to a particular belief, 3) behavioral commitment, which includes acting on the basis of belief; and 4) external commitment, which involves telling a person someone else believes that he holds a particular belief. It is reasoned that the greater the 
commitment, the greater will be his resistance to persuasion on a given issue.

Anchoring the belief to other cognitions. By this procedure, the belief in question is somehow linked to other cognitions thus requiring that any change in the original belief should also cause other changes which in turn affect a substantial portion of the entire belief structure. This kind of treatment is administered in the following ways: 1) linking the belief to accepted values, 2) linking to other beliefs, and 3) linking to a highly regarded source.

Inducing resistant cognitive states. Using this method, certain resistant cognitive states, i.e., any frame of mind which is not conducive to attitude change, are induced prior to a persuasive attack. Four methods of applying this procedure include: 1) inducing anxiety, 2) inducing an aggressive state in the individual, 3) raising the subject's self-esteem by treating him with a prior success experience, and 4) ideological preconditioning or "brainwashing."

Prior training in resistance to persuasion. This approach is characterized by educating or training people to sharpen their critical ability. Examples of this kind of approach 
include general education, training persons to be less susceptible to persuasive appeals, and training in the field of critical ability.

Reducing cognitive inconsistency. Up to this point, the approaches which have been discussed have all served to create a state of imbalance or incongruity in the individual; however, competing approaches function in the opposite manner. These methods attempt to reduce existing incongruity in the individual and thus aid the subject to resist persuasive appeals.

Source derogation is used as a pretreatment in anticipation of a message to be sent by the source in question. Simply stated, the credibility of the source of a forthcoming message is attacked, thus weakening the persuasive message and strengthening the opposing argument. Source credibility can also be diminished by employing the technique of denial.

The technique of denial requires that the source deny any responsibility for his assertion. Presumably, this would resolve the inconsistency which was incurred when the source made the imbalancing statement, by breaking the previously established link between the source and the assertion. 
The inoculation strategy. One approach that deserves a more detailed consideration is the strategy of inoculation. This was introduced by McGuire, et al in a series of experiments conducted during the early 1960's (McGuire, 1961; McGuire and Papageorgis, 1961; Papageorgis and McGuire, 1961). The term "inoculation" is borrowed from biology; when a patient is preexposed to a small dose of a disease virus, his system has a chance to build up antibodies in defense. Similarly, if a potential persuadee is preexposed to a mild persuasive attack, he is able to sharpen his resistance to future attacks. Two kinds of pretreatments have been used in conjunction with this approach; supportive and refutational pretreatments.

Supportive pretreatment messages attempt to strengthen the subject's attitude toward a particular issue. This is effected by providing the subject with information which supports his position.

Refutational pretreatments preexpose the subject to arguments which might be used against him in an upcoming persuasive attack, and, additionally, supply the subject with refutational arguments.

It is important to note that in these experiments, the beliefs which came under attack were "cultural truisms." These truisms were described by McGuire (1964) as: "beliefs that are so widely shared within the person's social milieu that he would not have heard them attacked, and 
indeed, would doubt that an attack were possible" (p. 201). Some examples of cultural truisms employed by McGuire are: "The effects of penicillin have been, almost without exception, of great benefit to mankind"; "It's a good idea to brush your teeth after every meal if at all possible." The use of cultural truisms allowed for an ideological environment which "would approximate, as regards inoculation theory, the health status of an organism raised in a germ-free environment" (p. 201).

There are some basic assumptions which should be discussed here. First, if the inoculation treatment is to be successful, the subject must be made to overcome his lack of experience in defending his belief. The reasons for this are quite simple: In the first place, since this belief is on the order of a cultural truism, the subject in all likelihood has never had the occasion to defend it, and secondly, due to the nature of the truism as being self-evident or beyond doubt, he is probably not motivated to practice the methods by which he can defend it.

There are three variables which affect the predictions one might make from the inoculation model. The first is the amount of threat which is contained in the defenses. Since supportive pretreatments only serve to bolster the "germ-free ideological environment"--to keep the already healthy body healthier--no element of threat is present. However, the refutational pretreatments do 
confront the subject with a sampler of arguments which are critical of the heretofore unassailable concept, and therefore do constitute a threat to the belief-structure of the subject. This threat is sufficiently potent to alert the "antibodies of the mind" so as to prepare the subject for a future attack, but are not strong enough to weaken the subject to the point that he abandons his belief or is unable to protect against another "dose."

In addition to the threat variable, another defensive variable, that of the participation of the subject, was examined in the experiments. There were two types of subject participation. Some subjects were given a defensive essay to read which had previously been prepared for them, while others were required to write their own essays. Some of the prepared essays contained arguments which were to be seen again in the persuasive attack (refutational-same), while others were composed of arguments which were not present in the later attack (refutational-different).

The time elapsed between pretreatment and subsequent persuasive attack constituted the third critical variable in these experiments. This interval ranged from a few minutes to one week. The major task was to minimize the time-related jeopardizing factors. 
Supportive v. refutational-same. McGuire and Papageorgis (1961) found that refutational-same pretreatments were more effective in conferring resistance to persuasion than were supportive pretreatments. Further, the supportive pretreatments were not clearly shown to be effective at all.

Refutational-same v. refutational-different. Refutational-same pretreatments were compared with refutational-different pretreatments in an experiment by Papageorgis and McGuire (1961). The refutational-same pretreatment was not found to be more effective than the refutational-different treatment. However, both pretreatments induced significantly more resistance to persuasion than was found in the non-pretreatment (control) group.

Combination of supportive and refutational.

McGuire (1961) found that the combination of refutationaldifferent and supportive pretreatments produced significantly greater resistance than did either treatment used alone. This finding was not the case when supportive pretreatments were combined with refutational-same treatments.

Language Intensity and Attitude Change According to Bowers (1964): "the intensity 
variable is an important one to communication research, for knowledge of intensity may warrant inferences about the attitudinal state of a communicator and his effect on the attitude of a receiver" (p. 415). Nevertheless, much of the research in the attitude change field has ignored this message variable. However, research on language intensity suggests the utility of incorporating the variable in attitude change research.

Several literary critics and semanticists have offered descriptions characterizing certain word-classes which express a communicator's values of goodness and badness. Thomas Dequincey (1890) used the term "language power"; Hayakawa (1949) offered "affective connotation"; Ogden and Richards (1952) coined the term "emotive meaning." These efforts suggest a semantic conceptualization of language intensity, one which would express both the direction and the strength of the communicator's attitude toward a subject. For the purposes of this investigation, the definition of language intensity offered by Bowers (1963) will be used. Language intensity is the quality of Ianguage which indicates the degree to which the speaker's attitude toward a concept deviates from neutrality.

Prior attitude and language intensity. Burgoon and Miller (1971) examined the relationship between prior 
attitude and language intensity... In the first experiment, it was predicted that persons who encoded a belief-discrepant message would use language which was of significantly lower intensity than persons who encoded a beliefcongruent message. In the second experiment, subjects were forced to write a counterattitudinal essay using language of high, moderate, or low intensity. It was predicted that attitude change would be directly related to the intensity of the message. In this manner, the high intensity message was predicted to produce the greatest attitude change, while the low intensity message was expected to produce the least attitude change. Their hypothesis was confirmed. Thus, language intensity, in this context, was directly related to attitude change. McEwen and Greenberg (1970) found a positive correlation between high intensity messages and favorable evaluations of the source and topic by the audience. In this study, it was hypothesized that: 1) greater attitude change will result from a high intensity persuasive message than a low intensity persuasive message; 2) sources credited with high intensity messages will be rated as more credible (dynamism, safety, and qualification) than sources credited with low intensity messages; and 3 ) the message itself will be more favorably evaluated (clarity, quality, logic) if it is of high rather than low intensity. All three hypotheses were confirmed. 
Rationale and Hypotheses

The role of language intensity has been shown to be of importance in effecting attitude change. It was reasoned that if high intensity messages were useful in facilitating persuasion, such message types should also prove effective when inducing an individual to resist persuasive attempts. Therefore, based upon the work of McGuire (1961), McEwen and Greenberg (1970), and Burgoon and Miller (1971), it was predicted that subjects would exhibit greater resistance to persuasion after having been exposed to a supportive pretreatment message of high intensity than would subjects who had been treated with a moderate or low intensity message, specifically:

$$
\begin{aligned}
& \mathrm{H}_{1}: \text { Given people exposed to supportive } \\
& \text { pretreatment messages, attitude } \\
& \text { change following exposure to a per- } \\
& \text { suasive attack using language of } \\
& \text { moderate intensity will vary } \\
& \text { inversely with the intensity of the } \\
& \text { pretreatment message. }
\end{aligned}
$$

The contrast effect. However, there is evidence which suggests a different hypothesis concerning the use of refutational pretreatment messages. Bowers (1963) hypothesized that speeches using highly intense language produce greater attitude change toward concepts than do those using language of low intensity. The results were opposite to this prediction. This was tentatively explained by Bowers as "a boomerang effect resulting from 
adverse audience reactions to the ethos of speakers taking unconventionally and unexpectedly strong positions" (p. 352). Thus, in this experiment, the prior attitude of the audience toward the speaker may have contributed to the unexpected outcome.

Burgoon (1970) found contrasting effects between response set and message evaluation. It was hypothesized that "a relevant message will be rated as more militant If it follows the induction of a militant response set than if it follows the induction of a non-militant set" (p. 265). In this study, subjects (blacks and non-blacks) were exposed to sets of militant or non-militant black names prior to reading a message written by the black vicepresident of Michigan State University. The message was of moderate nature. They were then asked to rate the message on scales bounded by "good-bad," "violent-nonviolent," "militant-non-militant," and "responsibleirresponsible." The hypothesis was supported by the experimental groups except for the white group. This group, which was given the militant name set prior to reading the moderate message evaluated the message as being less militant than did either the control group or the whites who were given the non-militant name set. Perhaps the anxiety felt by whites who were exposed to the militant name set was so greatly reduced by the unexpectedly moderate message that they evaluated it in a 
favorable manner. This is the contrast effect suggested by Brooks (1970) when he stated: "This principle assumes that we carry stereotypes into such social situations as the public speech. There, the speaker's behavior may be discrepant with our stereotyped expectations. If the discrepant stimuli cannot be assimilated or ignored, they are likely to be exaggerated in a listener's perception. So viewed, mere civil behavior on the part of Malcolm X may be perceived as extraordinarily genteel by an auditor who expects barbaric actions from a black nationalist" (p. 155). In addition, Brooks adds that this type of contrast effect may work upon a message for which there are those kinds of expectations.

Research by McEwen and Greenberg (1969) confirms the importance of assertion intensity upon the reliability of congruity theory predictions. It was found that such predictions would be more precise when the assertion linking source and topic was of the same intensity than if it were of a different intensity. Thus, for concepts of high intensity, language of high intensity would assure greater reliability for congruity theory predictions. The same would be true in situations of low intensity concept and low intensity language agreement.

In the refutational pretreatments, the subject is forwarned of arguments which may be used in an attempt to persuade him. Similarly, in the findings summarized 
above, the subjects had formed certain expectations prior to the given messages.

In the study conducted by Burgoon (1970), the "contrast effect," which occurred after subjects had been exposed to a militant name set, was caused by a conflict between the linguistic intensity of the experimental message and the prior attitude or expectations of the subjects. In the Brooks (1964) experiments, subjects reacted adversely to the "unexpectedly" strong messages delivered by the speakers. Further, the reliability of congruity theory predictions was increased in the study by McEwen and Greenberg (1969), when the language intensity of a persuasive message corresponded to the subjects' intensity of feeling toward the attitude issue. It was therefore reasoned that conflict between subject expectations and the linguistic structure of the persuasive message would yield a similar contrast effect.

Therefore, based upon the findings of Bowers (1963), McEwen and Greenberg (1969), Brooks (1970), and Burgoon (1970), a contrast effect is predicted between language intensity and attitude change when a refutational pretreatment is used, specifically:

$\mathrm{H}_{2}$ : Given people exposed to refutational messages, attitude change following exposure to a persuasive attack using language of moderate intensity will be related in a curvilinear manner to the language intensity of the pretreatment message, with those exposed to a moderate pretreatment message changing the least. 


\section{CHAPTER II}

\section{METHODS}

All experimental subjects were exposed to either a supportive or refutational pretreatment message prior to reading a counterattitudinal persuasive appeal. The messages were constructed so that in both the supportive and refutational conditions, messages of high, moderate, and low intensity were used. The counterattitudinal appeal contained language of moderate intensity. The pretest through posttest attitude change scores were compared for groups of subjects.

Subjects $(N=124)$ were members of introductory speech communication classes at San Fernando Valley State College. Subjects were asked to aid the researchers in an effort to develop a new sampling instrument.

Type of pretreatment message and the language intensity of the messages were the independent variables in this experiment. The overall design is presented in Figure 1. 


\begin{tabular}{|c|c|c|c|}
\hline & & Pretreat & Message \\
\hline & & Supportive & Refutational \\
\hline & High & $\mathbf{N}=21$ & $\mathbf{N}=14$ \\
\hline & Moderate & $\mathbf{N}=18$ & $\mathbf{N}=13$ \\
\hline & Low & $\mathbf{N}=11$ & $N=12$ \\
\hline & & Cont: & $N=24$ \\
\hline
\end{tabular}

Figure 1. The Experimental Design

Subjects

Students enrolled in lower division speech communication classes served as subjects for this experiment. Specifically, nine freshman public speaking and two sophomore communication classes participated in this experiment. All experimental materials were distributed to the students by their instructor.

Subjects who completed both pretest and posttest questionnaires, and received the experimental treatment, numbered 89; there were 24 people in the control group. Pretest through posttest attitude change was measured for each cell.

\section{$\underline{\text { PROCEDURE }}$}

Pretest

Five weeks prior to the actual experiment, subjects 
were administered a pretest questionnaire, ostensibly to solicit student opinion on a variety of issues. The instrument contained several issues of campus and nationwide scope. Each statement was followed by four seveninterval adjective pairs from the evaluative dimension of Osgood, Suci, and Tannenbaum (1957). The scales were bounded by Good-Bad, Pleasant-Unpleasant, Fair-Unfair, and Worthless-Valuable. The subjects were instructed to record a check-mark above the space which best represented their attitude toward the issue in question. Issues were scored by summing the scores on each of the four scales. Each scale could be scored from one to seven. A $\underline{I}$ rating indicated dissatisfaction with the issue in question, while a $I$ rating indicated strong acceptance of the attitude issue. The most negative score for a given issue was 28 while the most favorable position was a summated score of $\underline{4}$. Only those subjects who scored 14 or less were used in the experiment.

The issue yielding the most skewed distribution, with most people opposing the issue, called for San Fernando Valley State College to admit only those students who were either juniors or seniors; thus, it was selected as the experimental issue for this investigation. 
Independent Variables

Two independent variables were manipulated in this

study. The pretreatment message was dichotomized as

Supportive Pretreatment Message and Refutational Pretreatment Message. The language intensity variable was broken down Into three levels: High, Moderate, and Low. Subjects were assigned at random to each condition.

Inductions and Posttest

At the first experimental session, subjects in the experimental conditions were exposed to a pretreatment message. Subjects were asked to rate the pretreatment message as part of a problem analysis being conducted by the Communication Research Center at the college. Ostensibly, these messages were being prepared in an effort to assess community opinion, and the researchers were interested in developing a new sampling instrument for this purpose. The following was read to all subjects in the experimental condition:

This class has been selected to participate in a problem analysis sponsored by the Communication Research Center here at Valley state. We are currently working in an attempt to assess community opinion on various issues. Before this can be accomplished, however, an instrument must be developed in order to most accurately measure and record the attitudes of persons interviewed. We would like you to read the following message and rate it on several different scales. It is hoped that the development of new, 
innovative sampling techniques will yield the best possible representation of the beliefs and attitudes of the persons in this community. Than you very much for your cooperation in the development of this instrument.

Two days later, all subjects were asked to read and rate a counterattitudinal persuasive message. The same scales used in the pretest were utilized for evaluation of pretreatment and counterattitudinal message content.

Subjects in the control group were not exposed to the pretreatment messages. However, they were asked to read the counterattitudinal message and evaluate it in the same manner as the experimental groups. The counterattitudinal persuasive message read as follows:

SAN FERNANDO VALLEY STATE COLLEGE SHOULD LIMIT ENROLIMENT TO ONLY THOSE STUDENTS WHO ARE EITHER JUNIORS OR SENIORS

Limiting enrollment to only juniors and seniors would be a good policy for SFVSC to adopt. It would be a very good move from an economic standpoint, as the college would be able to save money by offering fewer lower level courses while expanding the number of upper division offerings. Less monies would be given out as scholarships, and this would be good in terms of expanding other programs.

Such a policy would have a welcome effect upon the level of scholarship. The office of admissions would have a good example of the student's ability to do college work, 
and could admit him accordingly:

Socially, the adoption of such a policy would be a welcome move, as it would bring the students closer together. This would have a very good effect, in that there would be increased support for student activities. This would be good in terms of increased student cooperation in scholarship and extracurricular activities. Such a policy would also be preferred in that it would facilitate communication between students and faculty. The more limited range of courses would have a welcome effect upon the amount of shared activities between students and faculty.

All things considered, such a policy would be preferred over the current system at SFVSC.

Preparation of the Experimental Material

The experimental issue was chosen after careful examination of the pretest questionnaires. The issue which was chosen was the third statement on the pretest instrument, "San Fernando Valley State College should only admit students who are either juniors or seniors." Initial student opinion ran heavily against this issue. It was necessary to utilize an issue on which student opinion was skewed, either positively or negatively, as the experiment was concerned with the effects of pretreatment strategies and varying intensity upon the already-held beliefs of the 
subjects. According to the pretest questionnaires, approximately 23 per cent of the respondents were against adopting the policy stated above.

The experimental messages were created utilizing a procedure developed by Burgoon and Miller (1971). Supportive and refutational messages were created which varied In language intensity to yield high, moderate, or low intensity messages.

In order to create the supportive pretreatment messages, a like-population of students were asked to give statements concerning the adoption of a policy whereby only juniors and seniors would be admitted to valley State. From the statements given by this group of students, a supportive message was constructed, omitting eleven critical words/phrases. These blanks were filled with words/phrases taken from a word list developed by Thurstone \& Jones (1955). These words had been quantified by means of successive interval scaling, thus yielding scale values which would allow estimates as to the directional deviation of the words/phrases from neutral point. The values in standard scores of the words/phrases ranged from +6.15 to -6.44 .

- Thus, each experimental message was differentiated only on the basis of the intensity of the language contained in the message. The following is an example of the Intensity manipulation: 
limfting enrollment to only juniors and seniors would be a policy for SFVSC.

The high intensity messages utilized the words very bad, the moderate intensity messages used bad, and the low intensity messages had the word poor inserted in this blank. The counterattitudinal message used language of moderate intensity. It was constructed prior to the refutational pretreatment message. Moreover, the arguments offered in this message were checked so that they did not touch upon the same points used in the supportive pretreatment message. Additionally, this facilitated the construction of the refutational pretreatment message, as the latter was an implicit rebuttal of the counterattitudinal message. The list of experimental words is presented in Table 1. The experimental messages are presented in Appendix A. 
Table 1. List of experimental words and weighted values

\begin{tabular}{|c|c|c|c|c|c|}
\hline $\begin{array}{l}\text { Dislike } \\
\text { extremely }\end{array}$ & 6.22 & Very good & 2.36 & Poor & 1.35 \\
\hline Excellent & 3.71 & Enjoy & 2.31 & \multirow{2}{*}{$\begin{array}{l}\text { Dislike } \\
\text { moderately } \\
\text { Like } \\
\text { moderately }\end{array}$} & 1.20 \\
\hline $\begin{array}{l}\text { Dislike } \\
\text { intensely }\end{array}$ & 3.31 & $\begin{array}{l}\text { Highly unfa- } \\
\text { vorable }\end{array}$ & 2.16 & & 1.12 \\
\hline Terrible & 3.09 & Bad & 2.02 & OK & .87 \\
\hline \multirow[t]{3}{*}{ Very bad } & \multirow[t]{3}{*}{2.53} & $\begin{array}{l}\text { Preferred } \\
\text { Good }\end{array}$ & $\begin{array}{l}1.96 \\
1.91\end{array}$ & $\begin{array}{l}\text { Like } \\
\text { slightly }\end{array}$ & .69 \\
\hline & & Welcome & 1.77 & \multirow{2}{*}{$\begin{array}{l}\text { Dislike } \\
\text { slightly }\end{array}$} & \multirow{2}{*}{.59} \\
\hline & & IIke & 1.38 & & \\
\hline
\end{tabular}


CHAPTER III

RESULTS

Perceived Importance of the Issue

In order to determine whether the subjects considered the task to be important, subjects completed a seven-interval semantic differential-type scale bounded by Important-Unimportant. With Important being scored $\underline{1}$, the mean score for all subjects was $\underline{3.49}$, with a standard deviation of 1.60. Apparently, subjects perceived the task as moderately important.

\section{Pretest}

After random assignment of subjects to experimental and control groups, a preliminary analysis was performed to ensure that no significant differences existed among the groups' pretest scores. An analysis of variance yielded no significant differences for the seven groups (Table 2). 
Table 2. Means, standard deviations, and analysis of variance of pretest attitude scores for experimental and control groups.

Condition

Mean Standard Deviation

High: Refutational

6.38

2.19

Moderate: Refutational

6.78

2.95

Low: Refutational

7.45

2.38

High: Supportive

6.23

2.97

Moderate: Supportive

6.69

3.38

Low: Supportive

6.00

2.50

Control

6.38

3.26

$\begin{array}{cccccc}\text { Source } & \text { SS } & \text { df } & \text { MS } & \text { F } & \text { P } \\ \text { Between } & 7.18 & 6 & 1.20 & .12 & <.05 \\ \begin{array}{l}\text { W1thin } \\ \text { Total }\end{array} & \frac{1004.19}{1011.37} & \frac{106}{112} & 9.47 & & \\ & & & \end{array}$

Experimental and Control Differences

Attitude change scores of the experimental and control groups were submitted to a simple analysis of variance. The overall amount of change and simple analysis of variance results are presented in Table 3. The results indicated that the groups differed significantly on the amount of pretest through posttest attitude change.

The specific differences between each experimental group and the control group were computed by means of a 
Scheffe's t-test (McNemar, 1969). The results indicated that significant differences existed between the High Intensity: Supportive, the Moderate Intensity: Refutational, and the Moderate Intensity: Supportive group and the Control group. No significant differences existed between the control group and the other experimental groups, as shown in Table 4.

Table 3. Attitude scores, amount of change, and analysis of variance of attitude change scores of experimental and control groups.

\begin{tabular}{|c|c|c|c|c|}
\hline Condition & & Pretest & Posttest & Change \\
\hline High: Refutational & & 6.38 & 11.08 & 4.70 \\
\hline Moderate: Refutational & & 6.78 & 8.57 & 1.79 \\
\hline Low: Refutational & & 7.45 & 12.00 & 4.55 \\
\hline High: Supportive & & 6.23 & 5.56 & -0.67 \\
\hline Moderate: Supportive & & 6.69 & 8.15 & 1.46 \\
\hline Low: Supportive & & 6.00 & 13.07 & 7.07 \\
\hline Control & & 6.38 & 12.94 & 6.56 \\
\hline Source & $\mathrm{df}$ & MS & F & $P$ \\
\hline $\begin{array}{l}\text { Between } \\
\text { Within } \\
\text { Total }\end{array}$ & $\frac{6}{106}$ & $\begin{array}{r}144.43 \\
16.59\end{array}$ & 8.71 & $<.01$ \\
\hline
\end{tabular}


Table 4. Analysis of differences of attitude change scores between each experimental group and control.

Condition*

Control $=6.56$

\begin{tabular}{lcl} 
& Mean Change & \multicolumn{1}{c}{$t$} \\
\cline { 2 - 3 }$H: R$ & 4.700 & n.s. \\
M:R & 1.789 & $3.76^{* *}$ \\
$\mathrm{~L}: \mathrm{R}$ & 4.545 & $\mathrm{n} . \mathrm{s}$. \\
$\mathrm{H}: \mathrm{S}$ & -0.667 & $5.28^{*}$ \\
$\mathrm{M}: \mathrm{S}$ & 1.462 & $3.2^{* *}$ \\
$\mathrm{~L}: \mathrm{S}$ & 7.071 & $\mathrm{n.s}$
\end{tabular}

**Using Scheffe's t-test, Critical $K=3.64$ at the .05 level

*H:R = High: Refutational

$\mathrm{M}: \mathrm{R}=$ Moderate: Refutational

$\mathrm{L}: \mathrm{R}=$ Low: Refutational

$\mathrm{H}: \mathrm{S}=$ High: Supportive

$\mathrm{M}: \mathrm{S}=$ Moderate: Supportive

L:S = Low: Supportive

Test of the Hypotheses

The two hypotheses in this experiment were tested by means of a two-way factorial analysis of variance. Data used for all analyses testing the hypotheses were the pretest to posttest attitude change scores of the subfects. The a priori significance level designated for all analyses was .05 . 
Hypothesis 1. The first hypothesis predicted an inverse relationship between intensity of the supportive pretreatment message and subsequent attitude change following a counterattitudinal persuasive attack, specifically :

Given people exposed to supportive pretreatment messages, attitude change following exposure to a persuasive attack using language of moderate intensity will vary inversely with the intensity of the pretreatment message.

Hypothesis 2. The second hypothesis predicted a curvilinear relationship between the intensity of the refutational pretreatment message and subsequent attitude change following a persuasive attack using language of moderate intensity, specifically:

Given people exposed to refutational messages, attitude change following exposure to a persuasive attack using language of moderate will be related in a curvilinear manner to the language of the pretreatment message, with those exposed to a moderate pretreatment message changing the least.

Table 5 indicates the differences in attitude change scores for the experimental groups. Significant differences were found between levels of language intensity in each message strategy. Additionally, the interaction between message strategy and language intensity was significant. There was no main effect difference between supportive and refutational strategies. 
Table 5. Analyses of variance for the mean change scores for experimental groups.

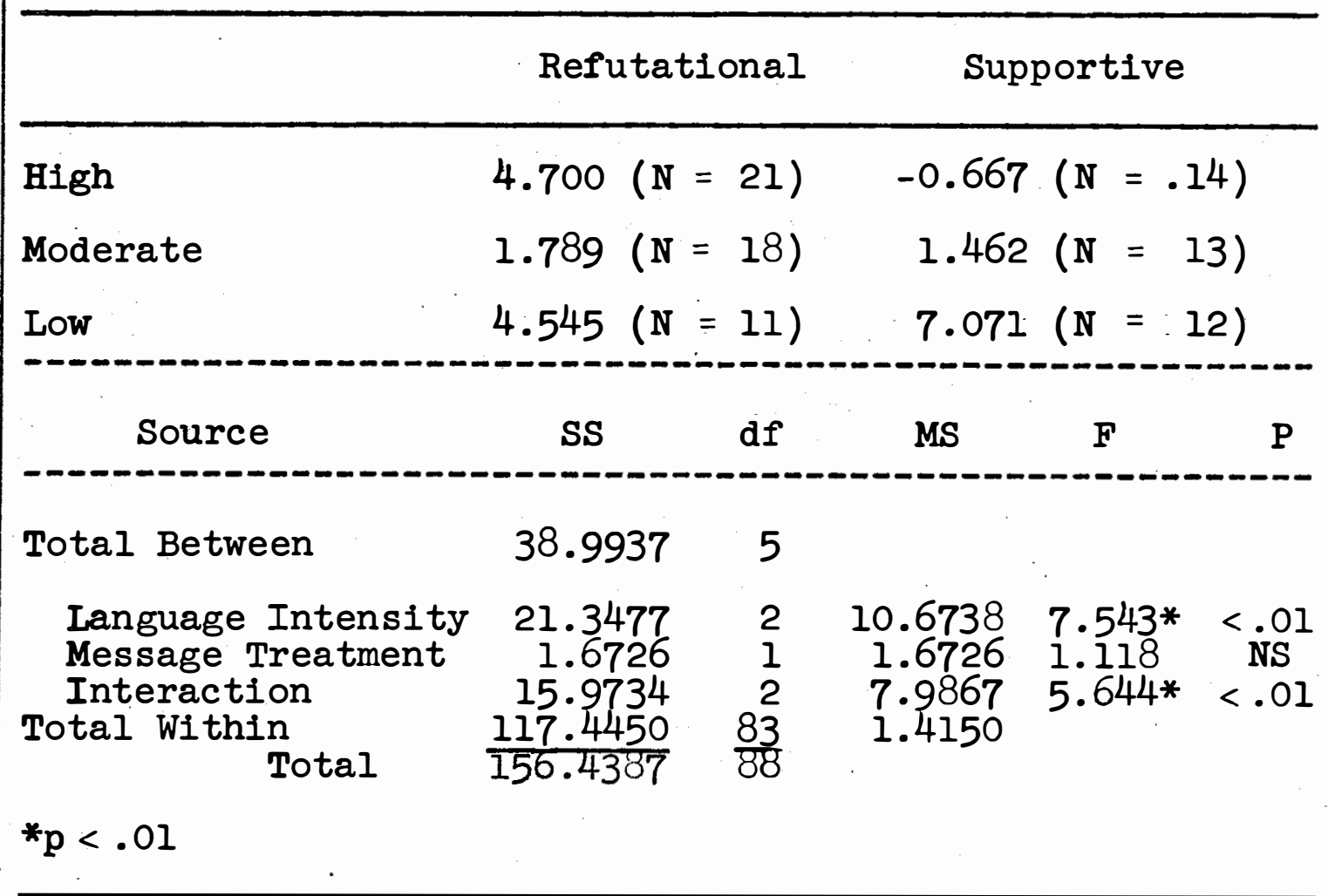

Because of the significant results obtained in the analysis of variance, individual comparisons were made using Scheffe's t-test. Table 6 summarizes those results. 
Table 6. Comparisons of mean change scores of experimental groups.

\begin{tabular}{|c|c|c|c|c|c|c|c|}
\hline Condition & Means & $\begin{array}{l}H: R \\
4.700\end{array}$ & $\begin{array}{c}M: R \\
1.789\end{array}$ & $\begin{array}{c}L: R \\
4.545\end{array}$ & $\begin{array}{c}H: S \\
-0.667\end{array}$ & $\begin{array}{r}M: S \\
1.462\end{array}$ & $\begin{array}{r}\text { L:S } \\
7.071\end{array}$ \\
\hline $\mathrm{H}: \mathrm{R}$ & 4.700 & -- & $8.62 *$ & 1 & NA & NA & NA \\
\hline$M: R$ & 1.789 & & -- & $6.09 *$ & NA & NA & NA \\
\hline$L: R$ & 4.545 & & & -- & NA & NA & NA \\
\hline $\mathrm{H}: \mathrm{S}$ & -0.667 & & & & -- & 4.99* & $16.54 *$ \\
\hline$M: S$ & 1.462 & & & & & -- & $11.78 *$ \\
\hline $\mathrm{L}: \mathrm{S}$ & 7.071 & & & & & & -- \\
\hline
\end{tabular}

*Using Scheffe's $\underline{t}$, the critical $\mathrm{K} .05=3.41$

The means were in the predicted direction in the supportive condition and the High Intensity condition was significantly different from the Moderate or Low; moreover the Moderate condition differed significantly from the Low. This clearly supports Hypothesis 1.

In the Refutational condition; the means were also in the predicted direction with the Moderate condition changing significantly less than either the High or Low; the High and Low Intensity conditions did not differ significantly. This presents clear support for Hypothesis 2 .

Supplementary Analyses 
linearity of the relationship between language intensity and attitude change in the supportive condition. The product-moment correlation yielded an $\underline{r}=.69$. Since Eta (.71) was not significantly greater than the obtained correlation, the observed relationship is a linear one. In the refutational condition, the obtained correlation was predictably low $(\underline{r}=.08)$ and $\underline{\text { Eta }}$ was significantly greater (.55); therefore, the relationship was curvilinear.

Finally, it was necessary to demonstrate that the counterattitudinal persuasive attack given without pretreatment messages changed attitudes. Scheffe's $\underline{t}$-test was computed to compare each experimental condition to the Control. Table 7 presents the results of those individual comparisons.

Table 7. Individual comparisons using Scheffe's t-test to compare each experimental group mean attitude change score to the control group.

Experimental Conditions Mean Change: $\underset{6.56}{\operatorname{Control}}(\mathrm{N}=24)$

$\begin{array}{lcl}H: R(N=21) & \frac{\text { Mean Change }}{4.70} & \text { N } \\ M: R(N=18) & 1.79 & 3.76 * \\ L: R(N=11) & 4.55 & \text { NS } \\ H: S(N=14) & -0.67 & 5.28 * \\ M: S(N=13) & 1.46 & 3.72^{*} \\ L: S(N=12) & 7.07 & \text { NS }\end{array}$

*Using Scheffe's t-test the critical k.05 $=3.64$ 
The High: Supportive, Moderate: Supportive, and Moderate: Refutational conditions demonstrated significantly less change than the Control conditions. 


\section{CHAPTER IV \\ DISCUSSION}

Research on the induction of resistance to persuasion has generally been concerned with demonstrating the relative efficacy of the supportive and refutational pretreatment message strategies. As a result of the emphasis placed upon pretreatment message types as the primary independent variable, little attention has been given to other message variables. The purpose of this study was twofold: 1) to examine the effects of language intensity upon inducing resistance to persuasion, and 2 ) the investigation of the effects of differing pretreatment strategies upon impending persuasive appeals.

In order to facilitate the investigation of both pretreatment strategy and language intensity effects, the inoculation strategy developed by McGuire (1961) was utilized. From the findings of this study, some extensions of the inoculation strategy seem warranted. In the McGuire and Papageorgis (1961) experiments, care was taken to maintain the biological analogy of the "germ-free ideological environment." As a result, "cultural truisms" --those topics which the subjects had not previously heard attacked--were used. Thus, subjects had not built up any defenses (antibodies) to combat such an attack. However, 
the topic used in the current investigation was of a different nature. Although no data were assimilated to verify this contention, it is likely the policy of admission advocated in the persuasive attack did not conflict with a cultural truism of the kind used by McGuire \& Papageorgis (1961). Thus the results of the current investigation extend the parameters of inoculation theory to include topics which are at least moderately controversial.

A further extension of inoculation theory, resulting from the findings of this investigation, is the utility of the supportive pretreatment message, and the importance of pretreatment message intensity. The effectiveness of both pretreatment strategles supports investigating both pretreatment message types. A view of refutational and supportive strategies as complementary rather than competitive might serve a better purpose.

McGuire (1961) found that the combination of supportive and refutational pretreatments induced significantly greater resistance to persuasion than did either treatment used alone. Research attempting to specify the antecedent conditions governing the construction of such combinations would extend the theoretical basis of inoculation theory. Specifically, a high intensity supportive message combined with a moderate intensity refutational message might yield significantly greater resistance to 
persuasion than either treatment used separately. The intensity of the counterattitudinal appeal could be varied as well. This suggestion could be easily incorporated in an experimental design.

The confirmation of the first hypothesis lends theoretic support to the contention concerning the generalizability of persuasion findings stated in Chapter 1; if high intensity messages were useful in facilitating attitude change, such message types should also prove effective when inducing an individual to resist persuasive attempts. This notion might also be examined with regard to other message variables. Further, the support of Hypothesis 1 lends credence to the operational definition of persuasion offered by Miller and Burgoon (1972), in which persuasion is viewed as both a facilitator and inhibitor of change. According to Miller and Burgoon (1972), "in labeling a communicative transaction as persuasive, the important issue concerns the type of relationship the persuador seeks to establish between his own attitudes and behaviors and those of the persuadee, not the types of messages encoded" ( $p .16)$.

Hypothesis 2 predicted that persons exposed to a refutational pretreatment message of moderate intensity would exhibit significantly less attitude change, following exposure to a counterattitudinal persuasive attack of moderate intensity, than would persons exposed to high- 
or low-intensity refutational pretreatment messages. The support given for this hypothesis is encouraging, especially in light of the contrast effect predicted in Chapter 1. The findings tend to confirm the post-hoc analyses of Bowers (1963), Brooks (1970), and Burgoon (1970). The operation of the contrast effect in this investigation suggests an intensity-agreement principle in persuasive

research. In other words, when receivers have certain expectations concerning the linguistic intensity of a speaker, the pretreatment message intensity should conform to those expectations when attempting to induce resistance to persuasion.

Bowers (1964) contends that the variable of intensity is important in communication research, as inferences concerning the attitudinal states of both the communicator and receiver may be made based upon knowledge of intensity. The findings presented in this study evidence the validity of considering the attitudinal states of the receiver, and the effects of message intensity upon such states. Additionally, the results of this investigation provide support for the utility of message intensity manipulations in attitude change paradigms.

Implications for Future Research

The next step in the investigation of the effects of language intensity manipulations in messages attempting to induce resistance to persuasion is the variance of the language intensity in the counterattitudinal persuasive 
appeal. Supportive pretreatment messages could be utilized in conjunction with counterattitudinal messages of varying intensity. In this manner, the effects of linguistic varlance within the persuasive appeal upon the persuasionInhibiting power of the supportive message could be exam1ned. The major value of such an experiment would be the investigation of the intensity-agreement principle suggested by the second hypothesis. Using refutational pretreatment messages of varying intensity prior to counterattitudinal messages similarly differentiated, the assertion concerning the effectiveness of intensityagreement could be better evidenced.

It was reasoned earlier that the greater the individual's level of commitment, the greater will be his resistance to persuasion on a given issue. In all experimental conditions, the level of subject commitment was that of public endorsement. Two increased levels of commitment described by McGuire (1964) are behavioral and extemal commitment. Further research, in which subjects commit themselves via behavioral or external commitment, could investigate the effects of differing commitment levels upon the results of language intensity manipulations. McEwen and Greenberg (1970) found that congruity theory predictions would be more precise when the assertion linking source and topic was of the same intensity than if it were of a different intensity. An investigation of the relationship between linguistic and concept 
intensity in a framework similar to that used in this experiment might yield useful findings in this vein. Such an effort would also shed light on the intensity-agreement principle suggested in this study.

To conclude, further investigation of means by which persons may become more resistant to persuasive appeals is currently needed. In the words of Miller and Burgoon (1972):

The persuasion literature has long been filled with "offensive game plans" which tell how to change a person, whether or not the change is good for him. It seems to us that in a time marked by a veritable explosion of persuasive communication, people need added resources to defend themselves against the barrage of persuasive attacks they face daily. Indeed, students of persuasion need to spend as much time and energy on the study of communication consumption as they have in the past on the study of communication production (p. 26).

Summary

A relatively small amount of research in persuasion has sought to discover how to make people more resistant to change. Research on the induction of resistance to persuasion has generally been concerned with demonstrating the relative efficacy of the supportive and refutational pretreatment message strategies. As a result of the emphasis placed upon pretreatment message types as the primary independent variable, little attention has been given to other message variables. The purpose of this study was twofold: 1) to examine the effects of language intensity upon inducing resistance to persuasion, and 2) the investigation of the effects of differing 
pretreatment strategies upon impending persuasive appeals. It was predicted that subjects would exhibit greater resistance to persuasion after having been exposed to a supportive pretreatment message of high intensity than would subjects who had been treated with a moderate or low intensity message.

It was also predicted that subjects exposed to a refutational message using language of moderate intensity would exhibit significantly more resistance to persuasion than would those subjects exposed to either a high or low intensity refutational pretreatment message.

The experimental messages were created utilizing a procedure developed by Burgoon and Miller (1971). Supportive and Refutational messages were created which varied in language intensity to yield high, moderate, or low intensity messages. Eleven key words/phrases taken from a word list developed by Thrustone and Jones (1955) were inserted into the experimental messages, to determine the intensity of the messages.

Attitude change was measured by subtracting pretest scores from posttest scores. Subjects evaluated the experimental issue on four seven-interval semantic differential-type scales.

The findings support both theoretical hypotheses. Subjects in the Supportive: High conditions exhibited significantly less attitude change than did those in either the Supportive: Moderate or Supportive: Low conditions. 
Moreover, those subjects in the Supportive: Moderate condition changed significantly less than did those subjects in the Supportive: Low condition. Subjects in the Refutational: Moderate condition exhibited significantly less attitude change than did subjects in either the Refutational: High or Refutational: Low conditions. Findings were discussed in terms of prior research in conferring resistance to persuasion. A number of research extensions, suggested by the findings of this study, were discussed. 


\section{BIBLIOGRAPHY}

Bettinghaus, Erwin P. Persuasive Communication, New York: Holt, Rinehart, and Winston, Inc., 1968.

Bowers, J.W. Language intensity, social introversion, and attitude change. Speech Monographs, 1963, 30, 345-352.

Bowers, J.W. Some correlates of language intensity. Quarterly Journal of Speech, 1964, 50, 415-420.

Brooks, Robert D. The generality of early reversals or attitudes toward communication sources. Speech Monographs, 1970, 37, 152-162.

Burgoon, M. The effects of response set and race on message interpretation. Speech Monographs, 1970, 37, 264-268.

Burgoon, M. and G.R. Miller Prior attitude and language intensity as predictors of message style and attitude change following counterattitudinal advocacy. Journal of Personality and Social Psychology, 1971, 20, 246-253.

DeQuincey, Thomas Collected Works, Edinburgh: 1890, 10, p. 220 .

Hayakawa, S.I. Language and Thought in Action New York: Harcourt, Brace and Co., 1949.

McEwen, W. J. and B.S. Greenberg Effects of communication assertion intensity. Journal of Communication, 1969, 19, 257-265.

McEwen, W.J. and B.S. Greenberg The effects of message intensity and receiver evaluations of source, message, and topic. Journal of Communication, 1970, 20, $340-350$.

McGuire, W.J. The effectiveness of supportive and refutational defenses in immunizing and restoring beliefs against persuasion. Sociometry, 1961, 24, 184-187. 
McGuire, W.J. Inducing resistance to persuasion. In I. Berkowits (Ed.), Advances in Experimental Social Psychology, Vol. I, New York: Academic Press, 1964, 191-229.

McGuire, W.J. and Demetrios Papageorgis The relative efficacy of various types of prior belief-defense in producing immunity against persuasion. Journal of Abnormal and Social Psychology, 1961, 62, $327-337$.

McNemar, Quinn Psychological Statistics, New York: John Wiley \& Sons, 1962, 286-287.

Miller, G.R. and M. Burgoon New Techniques of Persuasion, New York, in press 1972, 26.

Ogden, C.K. and I.A. Richards The Meaning of Meaning, loth Edition, New York: Harcourt, Brace and World, Inc., 1952, 239 .

Osgood, C.E., G. Suci, and P.H. Tannenbaum The Measurement of Meaning, Urbana, Illinois: University of Chicago Press, 1957.

Papageorgis, Demetrios and W.J. McGuire The generality of immunity to persuasion produced by pre-exposure to weakened counter-arguments. Journal of Abnormal and Social Psychology, 1961, 62, 475-481.

Thurstone, L.L. and L.V. Jones The psychophysics of semantics: an experimental investigation. Journal of Applied Psychology, 1955, 39, 31-39. 


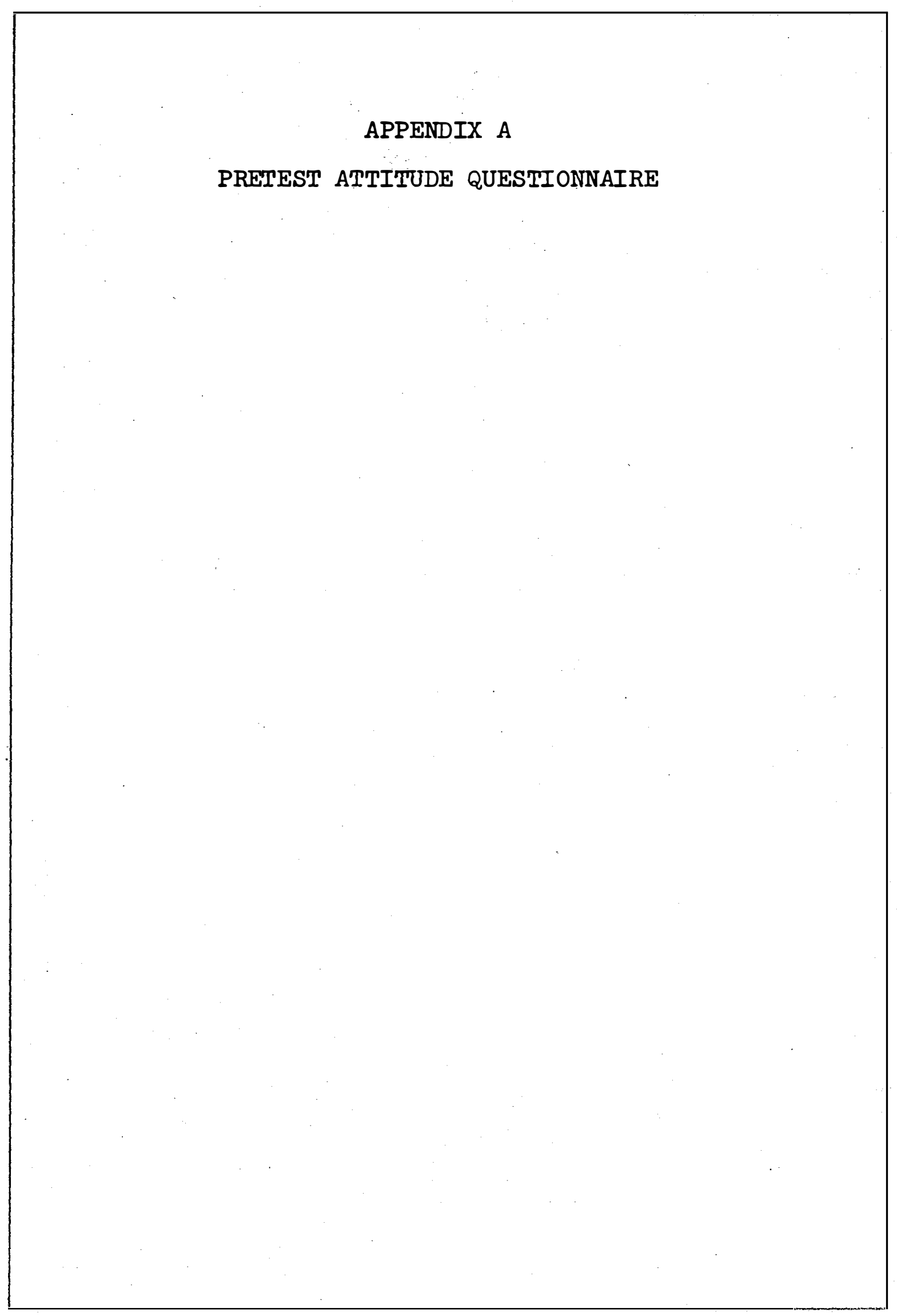




\section{SAN FERNANDO VALLEY STATE COLLEGE}

\section{STUDENT OPINION PROFILE}

Course Day/Time Name

The Communication Research Center at San Fernando Valley State College is attempting to solicit the opinions of students on a variety of current issues--campus and national--which may serve as a foci of a problem analysis. On each of the following pages you will find a number of issues followed by a series of scales.

PLEASE READ THE INSTRUCTIONS ON COMPLETING THESE SCALES VERY CAREFULLY

You will find several statements followed by several scales. Please mark each scale in the blank that BEST represents how you feel. For example, here is an item similar to those you will see:

"All universities and colleges should establish Chicano Studies Programs"

Good $:$<smiles>[3H][14CH2]I</smiles><smiles></smiles>
:

Your task is to place a check-mark (X) above the line that best indicates your feelings about the statement. For example, if you feel that the establishment of a Chicano Studies Program at all universities and colleges would be very good, you would mark the scale as follows:

Good $\mathrm{X}$ : : : :Bad

If you feel that such a move would be quite good, you would check as follows:

Good___ $:$ X

If you feel neutral or indifferent about the proposition, or if you feel that the scale is irrelevant to the proposition, you would check as follows:

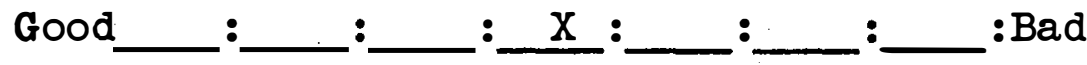

Remember: Never put more than one check-mark on a single scale and be sure that each check is in the middle of the line, not on the boundaries.

WORK RAPIDLY--RECORD FIRST IMPRESSIONS--DO NO CHANGE MARKS PLACE ONE "X" On EACH SCALE 


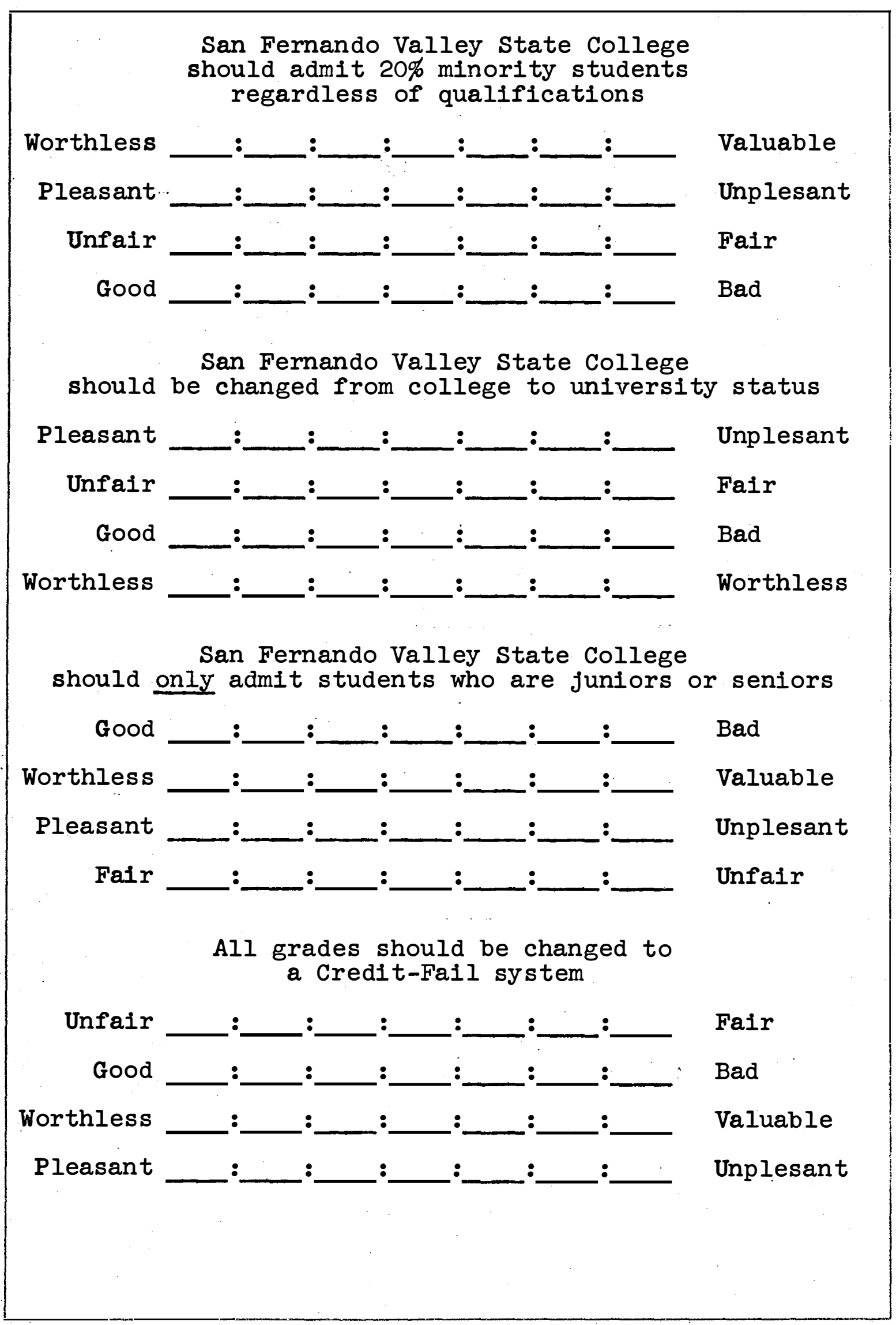


Tuition should be charged to all students in the State college system

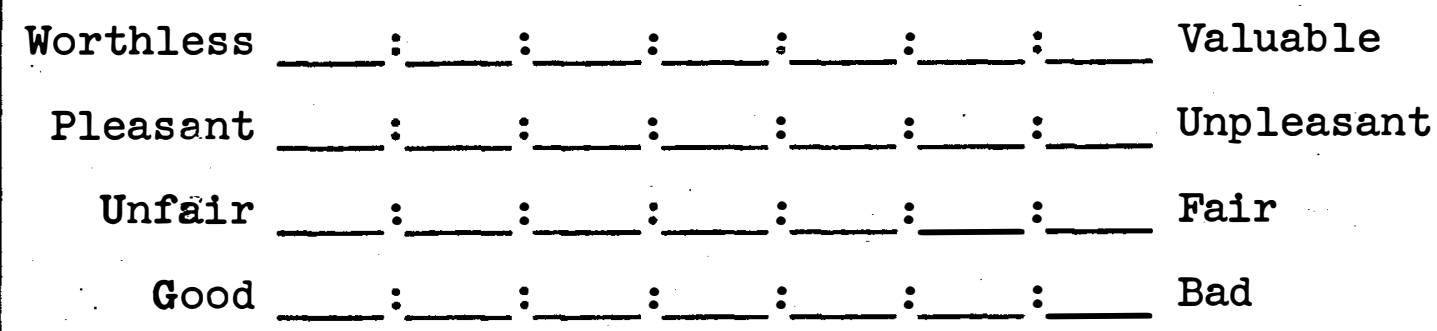




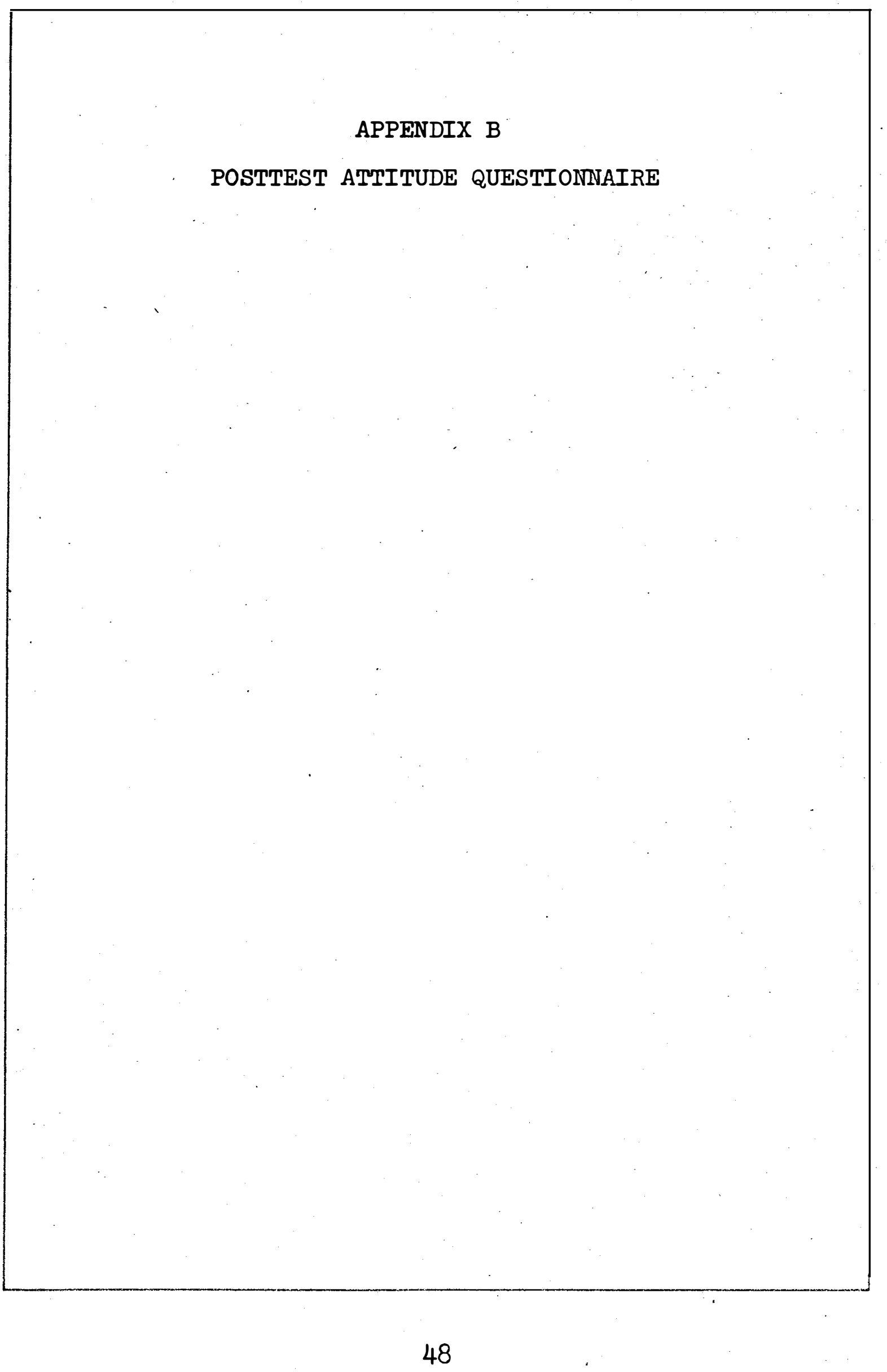




\section{SAN FERNANDO VALLEY STATE COLLEGE STUDENT OPINION PROFILE}

This class has been selected to participate in a problem analysis sponsored by the Communication Research Center at Valley State. We are currently working in an attempt to assess community opinion on various issues. Before this can be accomplished, however, an instrument must be developed in order to most accurately measure and record the attitudes of persons interviewed. We would like you to read the following message and rate it on several different scales.

It is hoped that the development of new, innovative sampling techniques will yield the best possible representation of the beliefs and attitudes of the persons in this community. Thank you very much for your cooperation in the development of this instrument.

Lawrence $\mathrm{J}$. Chase Project Director Communication Research Center San Fernando Valley State College 
SAN FERNANDO VALLEY STATE COLIEGE SHOULD LIMIT ENROLLMENT TO ONLY THOSE STUDENTS WHO ARE EITHER JUNIORS OR SENIORS

Limiting enrollment to only juniors and seniors would be a good policy for SFVSC to adopt. It would be a very good move from an economic standpoint, as the college would be able to save money by offering fewer lower level courses while expanding the number of upper division offerings. Less monies would be given out as scholarships, and this would be good in terms of expanding other programs

Such a policy would have a welcome effect upon the level of scholarship. The office of admissions would have a good example of the student's ability to do college work, and could admit him accordingly.

Socially, the adoption of such a policy would be a welcome move, as it would bring the students closer together. This would have a very good effect, in that there would be increased support for student activities. This would be good in terms of increased student cooperation in scholarship and extracurricular activities. Such a policy would also be preferred in that it would facilitate communication between students and faculty. The more limited range of courses would have a welcome effect upon the amount of shared activities between students and faculty.

All things considered, such a policy would be preferred over the current system at SFVSC. 


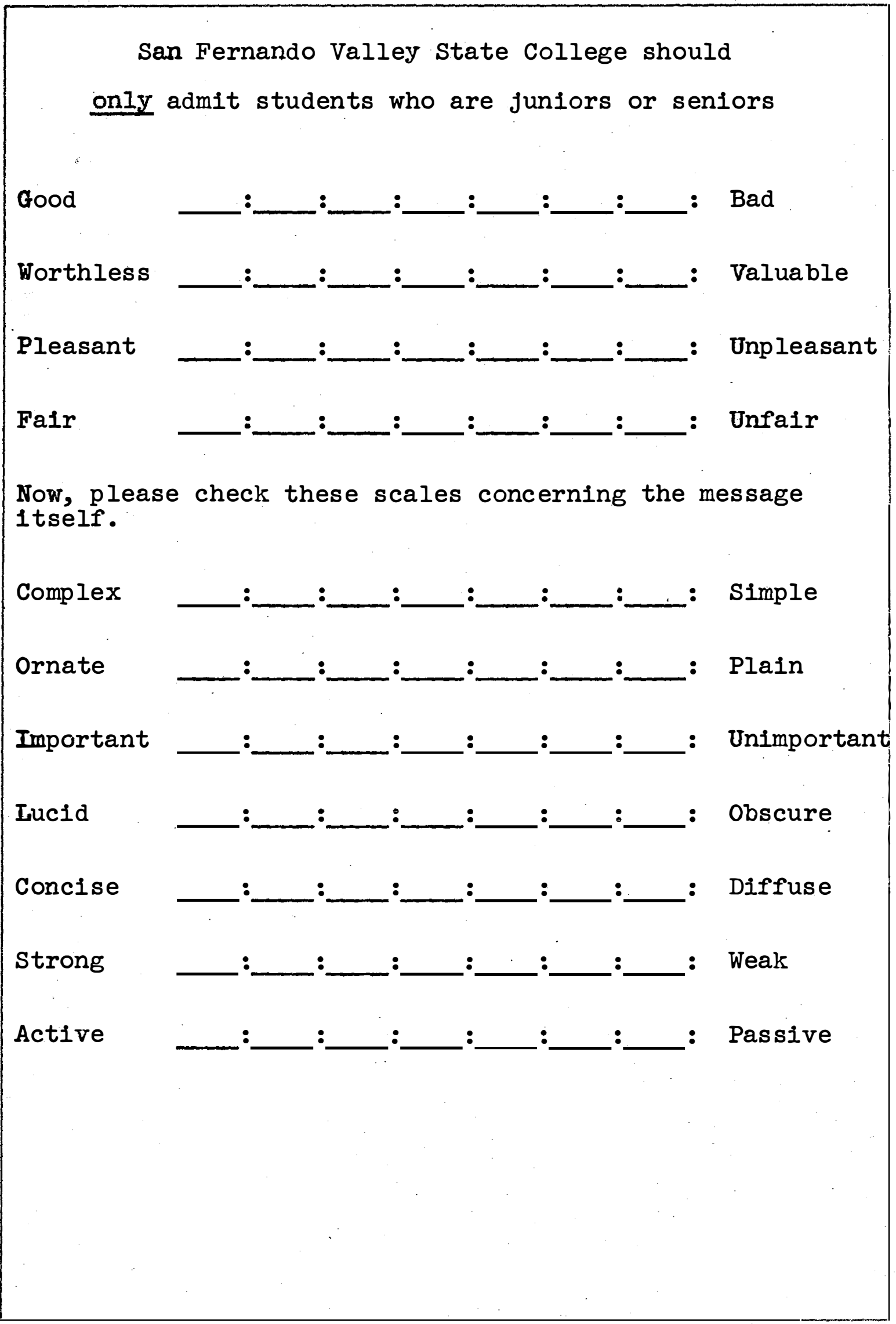




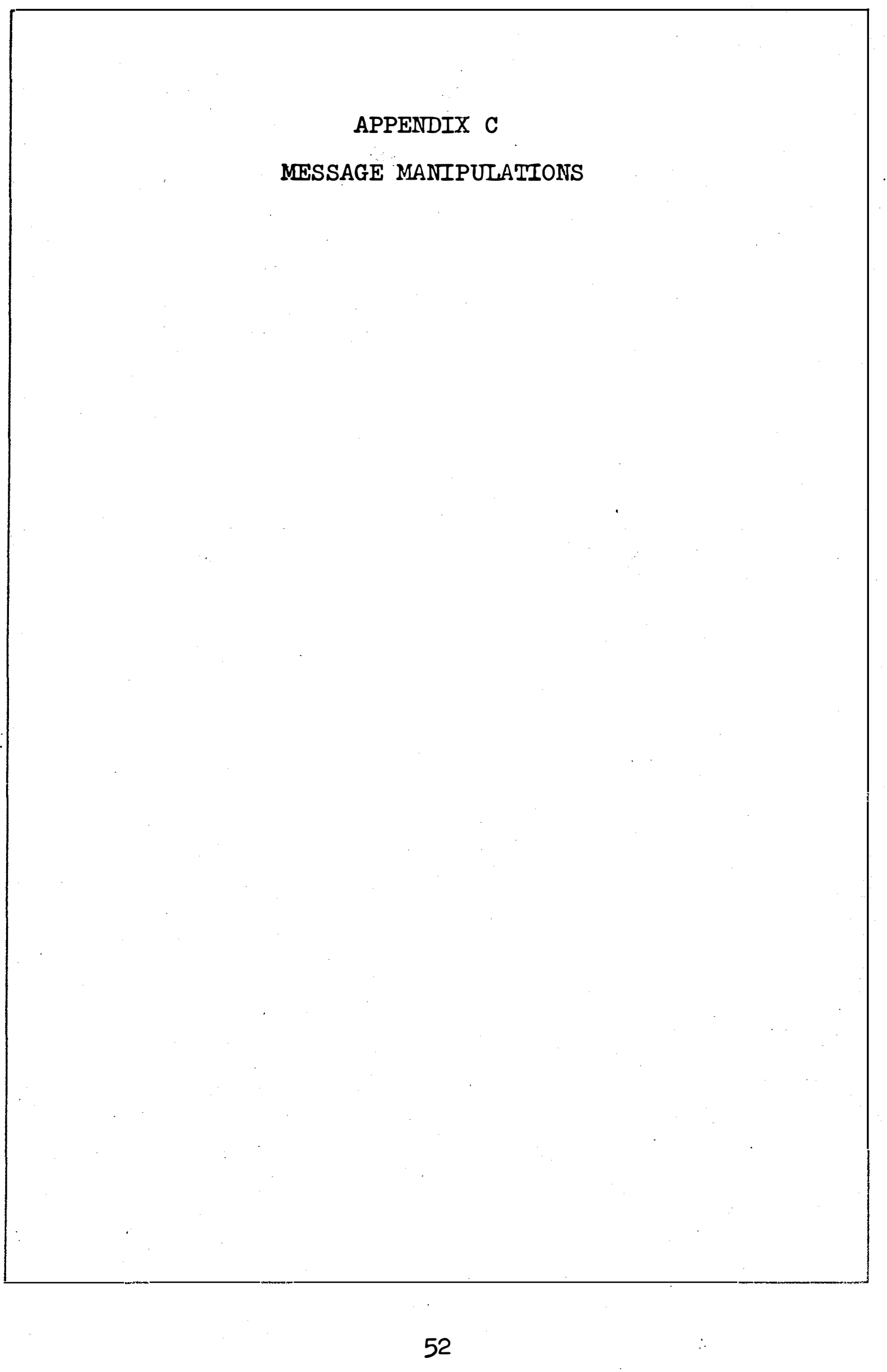




\section{[H1gh Supportive]}

SFVSC SHOULD NOT LIMIT ENROLLMENT TO ONLY THOSE STUDENTS WHO ARE EITHER JUNIORS OR SENIORS

I dislike extremely the idea of limiting enrollment at Valley State to only those students who are juniors or seniors. It would have a very bad effect upon the diversity of the student body. Students strongly like interacting with a wide variety of people.

This policy would have a terrible effect on the quality of student scholarship. I would dislike intensely the effect such a policy would have on the continuity of the college experience.

I would dislike extremely the fact that college students with excellent qualifications would be denied admission to Valley State simply because they had not completed enough units. To admit students based upon such criteria would be a terrible policy to adopt. This would be very bad from the standpoint of the high school graduate, whose qualifications were excellent, as well.

All in all, it is a very bad idea to limit enrollment to only juniors and seniors at Valley state. 


\section{[Moderate Supportive]}

SFVSC SHOULD NOT LIMIT ENROLLMENT TO ONLY THOSE STUDENTS WHO ARE EITHER JUNIORS OR SENIORS

I dislike the idea of limiting enrollment at Valley State to only those students who are juniors or seniors. It would have a highly unfavorable effect upon the diversity of the student body. Students enjoy interacting with a wide variety of people.

This policy would have a bad effect on the quality of student scholarship. I would dislike the effect such a policy would have on the continuity of the college experience.

I would dislike the fact that college students with good qualifications would be denied admission to Valley State simply because they had not completed enough units. To admit students based upon such criteria would be a bad policy to adopt. This would be highly unfavorable from the standpoint of the high school graduate, whose qualifications were good, as well.

All in all, it is a bad idea to limit enrollment to only juniors and seniors at valley state. 


\section{[Low Supportive]}

SFVSC SHOULD NOT LIMIT ENROLLMENT TO ONLY THOSE STUDENTS WHO ARE EITHER JUNIORS OR SENIORS

I dislike slightly the idea of limiting enrollment at Valley state to only those students who are juniors or seniors. It would have a poor effect upon the diversity of the student body. Students like moderately interacting with a wide variety of people.

This policy would have a poor effect on the quality of student scholarship. I would dislike moderately the effect such a policy would have on the continuity of the college experience.

I would dislike slightly the fact that college students with OK qualifications would be denied admission to Valley State simply because they had not completed enough units. To admit students based upon such criteria would be a poor policy to adopt. This would be poor from the standpoint of the high school graduate, whose qualifications were $\mathrm{OK}$, as well.

All in all, it is a poor idea to limit enrollment to only juniors and seniors at Valley state. 


\section{[High Refutational]}

SFVSC SHOULD NOT LIMLT ENROLLMENT TO ONLY THOSE STUDENTS WHO ARE EITHER JUNIORS OR SENIORS

Limiting enrollment to only juniors and seniors would be a very bad policy for SFVSC. It would be a terrible move from an economic standpoint, because the college would offer fewer lower division courses, and thus receive less state funds. There would be fewer scholarships available, and this would have a very bad effect upon our chances of receiving extra monies.

Such a policy would have a terrible effect upon the level of scholarship at SFVSC. Students would be admitted to upper division courses with only the very bad background that a junior college can provide. Thus admission can only be a guess based upon very bad evidence.

Socially, the adoption of such a policy would be a terrible move, as it would drive the students further apart. A greater emphasis would be placed on competition, and this is a very bad substitute for cooperation and interaction. This would have a terrible effect upon participation in student activities and would be very bad in terms of student faculty communication.

All things considered, I would dislike intensely adopting such a policy at SFVSC. 


\section{[Moderate Refutational]}

SFVSC SHOULD NOT LIMIT ENROLLMENT TO ONLY THOSE STUDENTS WHO ARE EITHER JUNIORS OR SENIORS

Limiting enroliment to only funiors and seniors would be a bad policy for SFVSC. It would be a bad move from an economic standpoint, because the college would offer fewer lower division courses, and thus receive less state funds. There would be fewer scholarships avallable, and this would have a highly unfavorable effect upon our chances of receiving extra monies.

Such a policy would have a bad effect upon the level of scholarship at SFVSC. Students would be admitted to upper division courses with only the bad background that a junior college can provide. Thus admission can only be a guess based upon bad evidence.

Socially, the adoption of such a policy would be a bad move, as it would drive the students further apart. A greater emphasis would be placed on completion, and this is a bad substitute for cooperation and interaction. This woùld have a highly unfavorable effect upon participation in student activities and would be bad in terms of student faculty communication.

All things considered, I would dislike adopting such a policy at SFVSC. 


\section{[Low Refutational]}

SFVSC SHOULD NOT LIMIT ENROLLMENT TO ONLY THOSE STUDENTS WHO ARE EITHER JUNIORS OR SENIORS

Limiting enrollment to only juniors and seniors would be a poor policy for SFVSC. It would be a poor move from an economic standpoint, because the college would offer fewer lower division courses, and thus receive less state funds. There would be fewer scholarships available, and this would have a poor effect upon our chances of receiving extra monies.

Such a policy would have a poor effect upon the level of scholarship at SFVSC. Students would be admitted to upper division courses with only the poor background that a junior college can provide. Thus admission can only be a guess based upon poor evidence.

Socially, the adoption of such a policy would be a poor move, as it would drive the students further apart. A greater emphasis would be placed on competition, and this is a poor substitute for cooperation and interaction. This would have a poor effect upon participation in student activities and would be poor in terms of student faculty communication.

All things considered, I would dislike moderately adopting such a policy at SFVSC. 


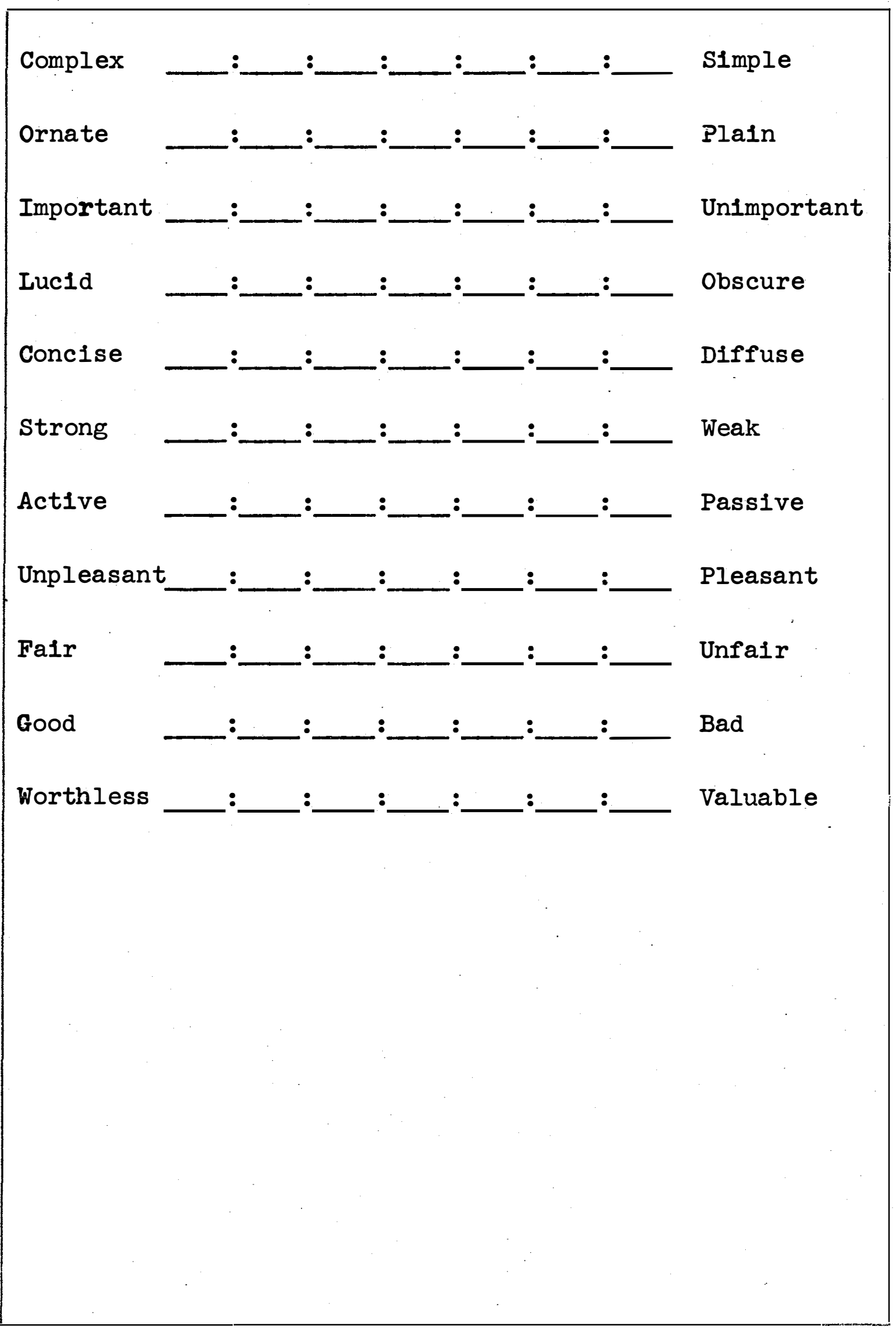

